\title{
Media studies: Evolution and perspectives
}

\author{
- Hem Raj Kafle
}

An interdisciplinary field of studies involves at least three concerns. The first is the question of its evolution from more than one origin. The second is its eclecticism - its reaches and scopes - the types of subjects, teachers, and students. And, the third is the general skepticism about its usefulness - the question of professionalism and employability. This essay is an attempt to address these fundamental concerns underlying the discourse on media studies as an interdisciplinary field ${ }^{1}$. I first outline the academic and theoretical roots of this field. Then I discuss its major disciplinary dimensions and critical issues.

\section{The foundations}

The roots of media studies are traceable in the inquiries about the relationship between media and culture. The early attempts to this direction started during the 1920s following the rise of mass media forms like radio networks, newspapers and magazines of mass circulation, and after mid 1930s with the advent of television media. The initial studies into media were influenced by the Eurocentric obsessions on high culture claimed by many to be "the best that has been said and thought." The media of the time were assigned the role of representing that high culture ignoring the world outside Europe and colonies of European powers. The period was marked by widespread British hegemony in media production and circulation with news agencies like Reuters and BBC, which projected the image of "media as powerful and influential, media as vehicles of nation-state or class propaganda, media as exemplars of modern technologically sophisticated professionalism" (Boyd-Barret and Rantanen,

1. This article is an extended version of Kafle, H. R. (2007). Media discourse: Evolution into academy. In N. M. Adhikary (Ed.), MBM anthology of media studies (pp. 17-27). Kathmandu: Communication Study Center.

Bodhi, 3 (1), 10-20. ISSN 2091-0479. (C) 2009 Kathmandu University 
2002, p. 217). Development of academic media discourse, nevertheless, was remarkably slow during these formative years because it lacked a specific theoretical direction as a result of what Denis MacQuail (2002) calls "the absence of a fixed disciplinary base" (p. 7).

Formally, media studies emerged from sociology and English studies and later took on vocational media training. From sociology, as Thornham and O'Sullivan (2004) report, “came a focus on patterns of social production and consumption and their relation with power and ideology, and corresponding empirical research skills" (p. 719). From English studies "came an emphasis on the skills and methods of textual analysis..." (ibid.). Sociological researches initially ignored media considering it to lack sufficiently 'serious' subject matters to justify special attention (McQuail, 2002, p. 6), in preference to common social problems like crime, poverty, race relations and family dislocations. But when the television media began to face unfriendly responses in Europe and America with the rise of soap operas and horror shows during 1950s and 1960s, and when scholars in educational psychology warned about TV being a deterrent to child rearing and family relationships, sociologists began to pay attention to examining the relationship between media and society. This gave way to the development of functionalist empirical study model. Researches under this model supported the view of society as "voluntaristic and self-directed, rather than ... manipulated and controlled by media" (McQuail, 2002, p. 7). In other words, researches within this model stood in defense of mass media and thus formed a kind of resistance against the view of renouncing media from domestic use. Media studies, however, departs from sociology in its "insistence on acknowledging the centrality of texts and modes of cultural representation" (Thornham \& O’Sullivan, 2004, p. 719).

Media began to get more scholarly attention within textual studies since the 1960s. The textual-linguistic models of literary studies such as formalism, semiotics/semiology and narratology had influenced the study of the nature and structure of linguistic

Bodhi, 3 (1), 10-20. ISSN 2091-0479. (C) 2009 Kathmandu University 
signs and codes used in media texts. Scholars of this mode defined the nature of narratives and observed the influence of cultural codes in constructing social reality. At the same time, reader response criticism saw the existence of what Stanley Fish called the "interpretive community" of readers of literary and media texts. This helped in the emergence of reception research and 'audience ethnography.' Reception researches "sought to understand in depth the personal and cultural significance of particular genres for particularly situated sets of audience members that could be characterized as interpretive communities"' (McQuail, 2002, p. 11). In addition, Stuart Hall's 1974 article on encoding/decoding model of communication was foundational for the 'reception paradigm' in media studies. Hall's model was an approach to communication as a process whereby 'encoded' [television] messages are received and 'decoded' by the audience to experience 'certain effects' (2002, p. 303). Hall's idea of the chain of encoding and decoding suggested the integration of production (message/representation) (technology/process),

content (effect/discourse/reception) in the study of media.

The advent of cultural studies in early 1970s brought media to the arena of academic studies within English studies programmes. A significant contribution in this direction was the establishment of the Birmingham Centre for Contemporary Cultural Studies in University of Birmingham in 1964, by English Scholars Richard Hoggart, Stuart Hall and Raymond Williams. The Centre, later known as The Birmingham School, introduced cultural studies in literary discourse leading to a shift from textual reading to cultural reading. Cultural studies integrated media with literary studies and expanded the latter into an interdisciplinary field with a wide variety of other areas like sociology, anthropology, postcoloniality, gender, race, ethnicity among others. As a critical movement against any specialized disciplinary standpoints, it explored alternative possibilities in the scholarly inquiries of socio-cultural issues. Cultural critics examined the role of any socializing force like mass media, "constantly asking new questions, looking for new

Bodhi, 3 (1), 10-20. ISSN 2091-0479. (C) 2009 Kathmandu University 
ways of theorizing and understanding cultural phenomena and their social implications" (Jordan and Weedon, 2006, p. 251). Pop culture studies, for example, was the pioneering strand of media studies during the 1960s.

Media studies that emerged from English through cultural studies took on an extended departure from traditional literary studies that advocated the canonization of Eurocentric culture as "the best that has been said and thought." In other words, the break from English studies came "with the interrogation and displacement of notions of the canon, and the need to secure an institutional space in which new, politically engaged and theorized kinds of textual analysis could take place" (Thornham \& O'Sullivan, 2004, p. 719). In connection with sociological and cultural inquiries, media studies transcended the specificity of disciplines. Consequently, it attained "two key qualities: its interdisciplinarity and its politically 'engaged' commitment" (ibid.).

Two major stimuli to this direction are poststructuralist and postmodernist approaches. Poststructuralsim, with the influence of deconstruction, challenges the traditional systems of meaning and message. Poststructuralists question the belief in "seeing the world in terms of specific, fixed and concrete entities," and consider the worldview as a "dynamic process of differentiation" (Thomson, 2006, p. 300). They regard no philosophy, nor meaning, as absolute. In its practical dimension, deconstruction suggests the need to search alternative meanings through a text's inherently conflicting codes and expressions. Applied in the study of media, such approach seeks the possibilities of multiple and infinite meanings in mediated messages. More broadly, it brings awareness that any communication process is not absolute in itself, nor are the communicated messages.

Postmodernism in the similar vein stands for multiplicity, chance and play of ideas. It comprehends the present time as the information age in which dominance of power is based not necessarily on the "politics of space," but on the "politics of

Bodhi, 3 (1), 10-20. ISSN 2091-0479. (C) 2009 Kathmandu University 
speed." Postmodernism promotes the worldview that the present is the age when identities are determined by "whose information is disseminated fastest" (Snipp-Walmsley, 2006, p. 410). It further recognizes the role of mass media in integrating people by reducing boundaries of space and time. It acknowledges the presence of multiple technologies as vehicles creating more spaces and more possibilities of switching across them.

\section{Media studies as a discipline}

According to Carl Eric Rosengren (2000), "As new media for communication have been created, the old ones have become specialized, but none have been completely eliminated" (p.1). This notion fully applies to media's evolution within academies. Media studies, for example, is a spacious field where societal changes and developments in media technologies merge continually.

It is difficult to say how long it takes for a subject to evolve into an academic discipline. Nevertheless, a few foundational factors can be traced behind the evolution. In the first place, the subject has to emanate sufficient amount of theoretical heritage through reasoning, experience and conceptualization over a stretch of time. Theories form actual bases for further inquiries and practices leading to the development of systematic disciplines. In other words, birth of theories helps store the knowledge of past and prepares guidelines for future inquires. Furthermore, the subject calls for simultaneous development of its related science and scholarship, which means the development of the actual subject matter along with the study of human aspects -- ideas, action, artifacts, history and so on (Rosengren, 2000, p. 4). This is more so with media as a discipline. The study of media is the study of their technology along with their socio-cultural implications.

Next, the subject should prove sufficiently scientific and human for universities to show readiness for its formalization as a discipline. In the process of formalization, academic institutions

Bodhi, 3 (1), 10-20. ISSN 2091-0479. (C) 2009 Kathmandu University 
often look towards its intellectual and professional value for individuals and societies. Media as academic discipline, in general, emerged through a combined effort of political scientists, psychologists and sociologists, who brought forth media and communication into the mainstream university discourses. And, they did it "often joining forces with the vocationally oriented schools of journalism which had a somehow longer history" (Rosengren, 2000, p. 24).

Today media studies has become an eclectic academic discipline with a closer orientation to the areas of humanities and social sciences. It enjoys both inter- and transdisciplinarity. Within it integrate as many areas as come under the rubrics of English studies and cultural studies, its parent disciplines, including hands-on exposure in the existing and emerging media technologies. Media studies can encompass a wide range of subjects from such foundational fields of studies as language, literature, history, geography, economics, political science, law, ethics, psychology, philosophy, sociology, anthropology, human rights, globalization, information management, entrepreneurship, public policy, tourism and sports, to core vocational areas like computer technology, new media technology, print technology, television studies, radio studies, journalism, photography, reporting, advertising and public relations. In fact, the list continues to expand provided universities plan to accommodate any areas that have direct bearing with media and their users.

What media studies curriculum can cover equals or surpasses what students and teachers in this discipline should know about social sciences, communication, journalism and digital technologies. The incorporation of the uses and effects of new media like internet and mobile technology makes it larger than cultural studies itself, and positions it as a theoretically rich technical field of studies, or vice versa. On the other hand, media studies programmes anticipate the production of media persons who have a commitment to independent media and bear a professional strength to help establish media as healthy contributors to the socio-economic developments. This

Bodhi, 3 (1), 10-20. ISSN 2091-0479. (C) 2009 Kathmandu University 
discipline equally aims to help develop quality media that can stand the test of time and counter unfriendly political shifts. The scope of media studies is broader than that of professional journalism and communication studies. Journalism is basically focused towards the production and broadcasting of media contents, whereas communication studies centers on the study of the various communication techniques and processes. The thrust of media studies is to study the nature and effects of mass media upon individuals and society thereby acquiring a distinct status within humanities and social science. At the same time, it encompasses the more professional areas like media production, mass communication and journalism. In this sense, media studies can be taken as a broader umbrella for journalism and mass communication studies.

Media studies adopts at least two semantic dimensions. The first continues the traditional notion of critical scholarship focusing on the study of form and effects of media. This still takes media studies as a component of cultural studies giving precedence to critical inquiries into the contents. The second dimension has a wider range of integrations of both theory and practice. Media studies in this sense is not limited to the study of contents produced elsewhere, but also sets compulsions to produce and prepare for critical inquiries within the stipulated university space and time. As a result, it acquires a thrust on producing employable graduates who have the skills and training to work in and across all major media platforms. Balanced within cultural studies and emerging media technologies, media studies in its contemporary dimensions has potential for constant modifications and thus manages to meet the needs of the convergence.

Besides training people for convergent media scenarios within a technically sophisticated context, media studies can serve in other areas more applicable in a developing countries. Foremost, it prepares media educators for secondary, higher secondary and university levels. The programme's thrust on the balance of theory, productivity and practice allows the preparation of professionals who have relatively more extensive

Bodhi, 3 (1), 10-20. ISSN 2091-0479. (C) 2009 Kathmandu University 
exposure on research, production and practice of media. Consequently, it reduces the politics of precedence between professors and professionals by virtue of the possibility of developing the qualities of both in individuals. Another contribution would be in the preparation of potential media entrepreneurs. In both cases above, a developing country is more benefitted. A full-fledged course in Media studies, if managed properly with the best theoretical and practical grounding on the major media platforms, may do nearly as much as the courses on journalism, communication studies, media science, computer science and literary studies can do jointly.

Three trends of media studies education are in existence at present. First, it is taught as a corollary to English Studies as a part of literary theory. English studies programs (within Tribhuvan University and Pokhara University in Nepal, for instance) include an elective in media either as media studies or as English for Mass Media. Such course aims at familiarizing the students with the common writing trends in print and electronic media. The second trend is of offering an integrated course like Film and Media Studies (as in University of Florida and University of California, Irvine, in the USA) and bringing a diversity of practical options. The third trend is that of a full degree program in Media studies (such as in Kathmandu University, Nepal; University of San Francisco, USA; and University of Malaya, Malaysia, among others). The program in this category takes on a confusing disciplinary location. Current practices show them as integral to the schools/faculties of humanities and social sciences. But given its blend and interconnection of disciplines - both theoretical and highly technical -- it can be established as separate, dynamic and accommodating interdisciplinary programme.

Media studies often elicits a general anxiety of employability. Traditional media studies is questioned for not assuring job opportunities when there has been "an increasing concentration on vocationalism and the discourses of "employability", (Thornham and O'Sullivan, 2004, p.717). Universities and

Bodhi, 3 (1), 10-20. ISSN 2091-0479. (C) 2009 Kathmandu University 
colleges may therefore be hard pressed addressing the dichotomy between preparing scholars, or 'products' of the media market. The anxiety of employability, however, is the byproduct of the notion that university education should cater to the changing needs of media industries, where versatility may pay less than specialization. Besides, unaware of its nature and scope, people often equate media studies with traditional journalism training. Thus those who have joined profession after attending short-term diploma, may see little worth in struggling under a four year long degree program. However, modern universities are not only the centres for learning and generating ideas, but also the manufacturers of human resources competent to work in the global scenario. The standard and quality of universities are judged on the basis of whether their graduates are able to enter into a career with potential for fast promotion. There is no quibble in the fact that universities should remain to be the centres of learning and research though sometimes market needs come as prominent agenda.

The pervasive influence of media in the way we think, act and identify ourselves continues to make them subjects of further critical studies. Recent systems of communication like internet, mobile phones and video games are believed to "reduce the face to face communication and increase feelings of loneliness and isolation" (Rosengren, 2000). Besides the presence and fear of digital divide, these systems are making social stratification even wider than before. Media studies gets firmer ground at such critical developments. It helps dispel the general stigma traditional societies have attached to journalism, by training people with more critical as well as accommodating mentality and skills.

New research paradigms in the academic discourse of media stem from invention and usage of new forms of media technology. So, wherever society complains of media's unfriendly influence, or adopts it as an inevitable element of everyday living, the field of media discourse expands. This expansion presupposes the inherently positive role of media in

Bodhi, 3 (1), 10-20. ISSN 2091-0479. (C) 2009 Kathmandu University 
human life. It is easy to say that future direction of media discourse will be influenced by the development of new media forms, but difficult to predict what new forms will emerge in the days to come. Given the technological boom in the recent years, especially in information and communication, the future of developed countries seems to be imperceptible as yet. Developing countries, however, will still have more to do.

\section{Conclusion}

Given the nature of the development of technologies and discourses, we can say in line with Rosengren, "Human communication will remain much the same, but there will be more of it" (2000, p. 199). There will be more researches on media processes and effects in the future, undoubtedly with greater focus on the computerized communication systems. Technological developments will make researches more dependent on computerized data, disseminated online through digital libraries and networks around the globe. People will be required to devise new techniques of research; new theories will emerge through these researches thereby adding to a greater storage of knowledge.

The present trend in the education and practice of media shows that well-trained graduates with concentration on the convergence show greater adaptability in working across platforms. Taken form the standpoint of developments in technologies and alternatives, media studies graduates appear to secure more opportunities. A very optimistic point, in the words of Quin and Filak (2005), is this: "The future is bright for journalists and journalism, and that future offers multiple possibilities for people who are prepared" (p. 205). Little noticed at present is the potential of media studies graduates to work both off-screen and on-screen, or say, their capacity for omnipresence.

Bodhi, 3 (1), 10-20. ISSN 2091-0479. (C) 2009 Kathmandu University 


\section{References}

Boyed-Barret, O., \& Rantanen, T. (2002). Theorizing the news agencies. In D. McQuail (Ed.), McQuail's reader in mass communication theory (pp. 215-221). New Delhi: Sage Publications.

Hall, S. (2002). The television discourse: Encoding and decoding. In D. McQuail (Ed.), McQuail's reader in mass communication theory (pp. 2-20). New Delhi: Sage. Jordan, G., \& Weedon, C. (2006). "Literature into culture: Cultural studies after Leavis." In P. Waugh (Ed.), Literary theory and criticism: An Oxford guide (pp. 245-255). New York: Oxford University Press.

McQuail, D. (2002). General introduction. In D. McQuail

(Ed.), McQuail's reader in mass communication theory (pp. 2-20). New Delhi: Sage Publications.

Quinn, S., and Filak, V. F. (2005). Where do we go from here?

In S. Quinn, and V. F. Filak (Eds.), Convergent journalism (pp 205-212). New York: Focal Press.

Rosengren, K. E. (2000). Communication: An introduction. New Delhi: Sage Publications.

Snipp-Walmslay, C. (2006). Postmodernism. In P. Waugh (Ed.), Literary theory and criticism: An Oxford guide (pp. 405-426). New York: Oxford University Press.

Thomson, A. (2006). Deconstruction. In P. Waugh (Ed.), Literary theory and criticism: An Oxford guide (pp. 298-318). New York: Oxford University Press.

Thornham, S., and O'Sullivan, T. (2004). Chasing the real: 'Employability' and the media studies curriculum. Media, Culture and Society, 26 (5), 717-736. 